\title{
Influence of Irradiation Time on Structural, Morphological Properties of ZnO-NRs Films Deposited by MW-CBD and Their Photodiode Applications
}

\author{
Saliha Ilican, ${ }^{1}$ Kamuran Gorgun, ${ }^{2}$ Yasemin Caglar, ${ }^{1}$ and Mujdat Caglar1 \\ ${ }^{1}$ Department of Physics, Faculty of Science, Anadolu University, 26470 Eskisehir, Turkey \\ ${ }^{2}$ Department of Chemistry, Faculty of Arts and Science, Eskisehir Osmangazi University, 26480 Eskisehir, Turkey \\ Correspondence should be addressed to Yasemin Caglar; yasemincaglar@anadolu.edu.tr
}

Received 2 May 2017; Accepted 17 July 2017; Published 22 August 2017

Academic Editor: Miguel A. Garcia

Copyright (C) 2017 Saliha Ilican et al. This is an open access article distributed under the Creative Commons Attribution License, which permits unrestricted use, distribution, and reproduction in any medium, provided the original work is properly cited.

\begin{abstract}
Microwave-assisted chemical bath deposition (MW-CBD) was used to deposit zinc oxide nanorods (ZnO-NRs) films by using different microwave irradiation time. The films exhibit a good crystallinity having a hexagonal wurtzite phase formation. Although the dominant preferred orientation was not observed for the $\mathrm{ZnO}-5$ and $\mathrm{ZnO}-10, \mathrm{ZnO}-8$ showed (002) preferred orientation. The emission scanning electron microscope (FESEM) showed almost randomly oriented hexagonal nanorods on the surface. A slight decrease in the length of the observed hexagonal nanorods due to the increase in the irradiation time was observed, changing from $550 \mathrm{~nm}$ to $300 \mathrm{~nm}$. The $p-S i / n-Z n O-N R s$ heterojunction photodiodes were fabricated. The current-voltage characteristics of these photodiodes were investigated under dark and different illumination intensity. An increase in the reverse current with increasing illumination intensity confirmed that the fabricated photodiodes exhibited a photoconducting behavior. In addition, the barrier height and series resistance values of the photodiodes were determined from capacitance-voltage measurements.
\end{abstract}

\section{Introduction}

In modern materials science, nanostructured $\mathrm{ZnO}$ films are versatile material to make in numerous novel applications, owing to their several unique features, including the wide band gap $(3.37 \mathrm{eV})$, good transparency and electrical conductivity, excellent electron mobility, and low thermal expansion. So they have been extensively studied and applied in many applications, such as sensors [1,2], light-emitting diodes [3, $4]$, thin film transistors $[5,6]$, photodetectors [7], and solar cells $[8,9]$.

Over the past two decades, materials scientists have developed various synthetic means for preparing nanostructured $\mathrm{ZnO}$ films. These films in forms of nanoparticle, nanowire, nanorod, nanotube, nanoflower, and so on can now be easily obtained with most of methods and techniques, such as sol-gel [10-12], spray pyrolysis [13, 14], chemical bath deposition (CBD) [15], SILAR [16], electrochemical deposition $[17,18]$, sputtering $[19,20]$, atomic layer deposition [21], and microwave-assisted chemical bath deposition
(MW-CBD) [22]. Currently world-wide works continue intensively in both the basic and applied areas and with the advent of modern oxide film deposition methods [23]. The deposition method of the film is the very first important step in material research. So these developments are very important because the better deposition methods would lead to the better quality of the film. There are a several solution methods for deposition of high quality films. MWCBD method is one of them $[22,24,25]$. Some of the most important advantages of this method are to have short deposition time and that does not require any further thermal annealing, unlike conventional CBD.

To the best of our knowledge, there are no accessible reports related to photodiode applications of the $\mathrm{ZnO}$ NRs films deposited by MW-CBD. But, there are many reports about $\mathrm{ZnO}$ photodiodes fabricated by other methods. Among these reports, Orak et al. [26] deposited $\mathrm{ZnO}$ layer onto $n$-Si by atomic layer deposition technique. They fabricated $\mathrm{Au} / \mathrm{ZnO} / \mathrm{n}$-Si photodiode and investigated its current-voltage and capacitance-voltage characteristics. Authors 
reported that the photovoltaic parameters of device such as short circuit current $\left(I_{\mathrm{sc}}\right)$, open circuit voltage $\left(V_{\mathrm{oc}}\right)$, fill factor (FF), and conversion efficiency $(\eta)$ are found to be $342 \mathrm{mV}, 34.7 \mu \mathrm{A}, 32 \%$, and $0.48 \%$ under $100 \mathrm{~mW} / \mathrm{cm}^{2}$ light intensity. Al-Hardan et al. [27] prepared $\mathrm{ZnO}$ nanorods on $\mathrm{p}$ type silicon ( $\mathrm{p}-\mathrm{Si}$ ) using low-temperature hydrothermal processing. They investigated current-voltage and capacitancevoltage characteristics of fabricated photodiodes. Authors reported that the rectifying ratio is found to be 370 at $10 \mathrm{~V}$. Yakuphanoglu et al. [28] used the sol-gel spin coating method to prepare nanostructure $\mathrm{ZnO}$ film on to $\mathrm{p}$-Si substrate. In their report, it was emphasized that the nanostructure of the $\mathrm{ZnO}$ improved the quality of $\mathrm{ZnO} / \mathrm{p}$-Si interface. They found the ideality factor and barrier height of the diode to be 3.18 and $0.78 \mathrm{eV}$, respectively. They also reported that the diode showed a photovoltaic behavior with a maximum open circuit voltage $V_{\mathrm{oc}}$ of $0.26 \mathrm{~V}$ and short-circuits current $I_{\mathrm{sc}}$ of $1.87 \times$ $10^{-8} \mathrm{~A}$ under $100 \mathrm{~mW} / \mathrm{cm}^{2}$. Yuan and Ren [29] fabricated well-aligned $\mathrm{ZnO}$ nanowire arrays on ITO substrates by a spray coating process. In their work, the crystallinity, structure, and morphology of $\mathrm{ZnO}$ nanowire arrays were characterized. They investigated current-voltage characteristics of fabricated photodiodes. Authors reported that the $\mathrm{RR}$ of this photodiode increased with increasing illumination power from 40 to $100 \mathrm{~mW} / \mathrm{cm}^{2}$. And also, $\mathrm{Au} / \mathrm{ZnO} / \mathrm{n}-\mathrm{GaAs}$ Schottky barrier diodes were fabricated by Tan et al. In their works, it was emphasized that the device exhibited a photodiode behavior and the serial resistance exhibited a decreasing trend with increasing illumination [30].

In the present study, $\mathrm{ZnO}$-NRs films have been deposited by MW-CBD at different irradiation times (5, 8, and $10 \mathrm{~min}$ ) and fabricated a photodiodes based $\mathrm{ZnO}$. The effect of irradiation time on the structural, morphological properties of $\mathrm{ZnO}$ film has been investigated and the electrical properties of $p$-Si/n-ZnO-NRs photodiodes fabricated by MW-CBD method have also been investigated.

\section{Experimental Details}

The ZnO-NRs films were deposited by MW-CBD method onto silicon substrates which is p-type (boron-doped) single crystal with (100) surface orientation, having a thickness of $600 \mu \mathrm{m}$ and a resistivity of $1-10 \Omega \mathrm{cm}$. Before the deposition process, $\mathrm{p}$-Si substrates were cleaned chemically by using deionized water and acetone and then were dried with $\mathrm{N}_{2}$ flow. After that they were etched in argon plasma ambient for 10 minutes in HARRICK Plasma Cleaner. Zinc nitrate hexahydrate $\left(\mathrm{ZnN}_{2} \mathrm{O}_{6} \cdot 6 \mathrm{H}_{2} \mathrm{O} ; \mathrm{ZnNt}\right)$ and hexamethylenetetramine $\left(\mathrm{C}_{6} \mathrm{H}_{12} \mathrm{~N}_{4}\right.$; HMTA) in equal molarity were dissolved in $100 \mathrm{ml}$ deionized water. The certain amount of HMTA catalyst was added to accelerate the reaction, and supply of $\mathrm{OH}^{-}$as capping agent promotes anisotropic growth. The solution was stirred at room temperature for $20 \mathrm{~min}$. The substrate was inserted in a beaker containing this solution and transferred into a CEM Mars 6 model microwave oven and irradiated at $600 \mathrm{~W}$ for different times (5, 8, and $10 \mathrm{~min})$. Therefore, the obtained samples are named $\mathrm{ZnO}-5, \mathrm{ZnO}-$ 8, and $\mathrm{ZnO}-10$. After MW-CBD treatment, coatings were removed from the solution and rinsed with deionized water and dried under $\mathrm{N}_{2}$ flow. Finally, coatings dried at $60^{\circ} \mathrm{C}$ for 1 h. By evaporation of high-purity aluminum (Al, 99.999\%) under the pressure of $4.5 \times 10^{-5}$ Torr, metal contacts were formed on the films. The contacts, which were formed in the form of circular dots of $1 \mathrm{~mm}$ in diameter, have $100 \mathrm{~nm}$ thicknesses. In this coating process, we used silver paint for a bottom contact after the coating of $\mathrm{ZnO}$ because of not forming the ohmic contact on the back surface of silicon wafer before MW-CBD process. Also, any annealing process was not applied to get low resistivity of ohmic contact because of having high eutectic temperature $\left(<830^{\circ} \mathrm{C}\right)$ of silver, because such a high temperature can change all the physical properties of the samples. But, not applying any annealing process will lead to the occurrence of a high series resistance. The obtained photodiodes are named PD-5, PD8 , and PD-10. The schematic diagram of these heterojunction diodes is given in Figure 1.

The structure and crystalline quality of the $\mathrm{ZnO}-\mathrm{NRs}$ films were determined by X-ray diffraction (XRD) using $\mathrm{CuK}_{\alpha}$ radiation $(\lambda=1.5418 \AA$, Bruker D2 Phaser $)$ at RT with a scanning step size of $0.02^{\circ}$. The surface morphologies of the $\mathrm{ZnO}$-NRs films were analyzed by field emission scanning electron microscopy (Zeiss Ultraplus, FESEM). The currentvoltage $(I-V)$ and capacitance-voltage $(C-V)$ measurements were taken with Keithley 4200SCS and Signatone Probe Station. The intensity of illumination measurements was carried out using a solar simulator (Sciencetech).

\section{Results and Discussion}

The crystallinity of the $\mathrm{ZnO}$-NRs films was analyzed by the XRD method. Figure 2 shows the XRD spectra of all the films. The characteristics peaks of zincite phase (JCPDS card file number 36-1451, zincite phase) that have hexagonal wurtzite structure are shown in this figure. Five peaks between $30^{\circ}$ and $60^{\circ}$ for the $\mathrm{ZnO}$ are indicated (100), (002), (101), (102), and (110) planes. The observed peaks at about $32.7^{\circ}, 54.3^{\circ}$, and $56.5^{\circ}$ belong to $\mathrm{Si}$ substrate. The preferred orientation of the $\mathrm{ZnO}-\mathrm{NRs}$ films was evaluated by the texture coefficient (TC) calculated from the XRD data using the well-known formula [31]. The bar graphs inset in Figure 2 show the calculated TC values of $\mathrm{ZnO}-\mathrm{NRs}$ films irradiated with different irradiation times for each main five (hkl). As seen in this graph, although a dominant preferred orientation has not been observed for ZnO-5 and $\mathrm{ZnO}-10, \mathrm{ZnO}-8$ has (002) preferred orientation. Also, the peak, which belongs to Si substrate at 32.7 degree and is observed in the XRD patterns of $\mathrm{ZnO}-5$ and $\mathrm{ZnO}$ 10 , disappears in the $\mathrm{ZnO}-8$ pattern, meaning that its coating property is better than the others.

The surface morphology of the $\mathrm{ZnO}-\mathrm{NRs}$ films was examined by using FESEM. Both top view and $50^{\circ}$-tilted view FESEM images of the $\mathrm{ZnO}-\mathrm{NRs}$ are presented in Figure 3(a)-3(f). In these figures, for each film deposited by MW-CBD at three different irradiation times, almost randomly oriented hexagonal nanorods on the surface are observed. At the end of the detailed SEM investigations, we can easily say that almost all the surface was coated with ZnO-NRs, although very few voids on the surface were detected. Particularly, the amount of these voids in $\mathrm{ZnO}-10$ 


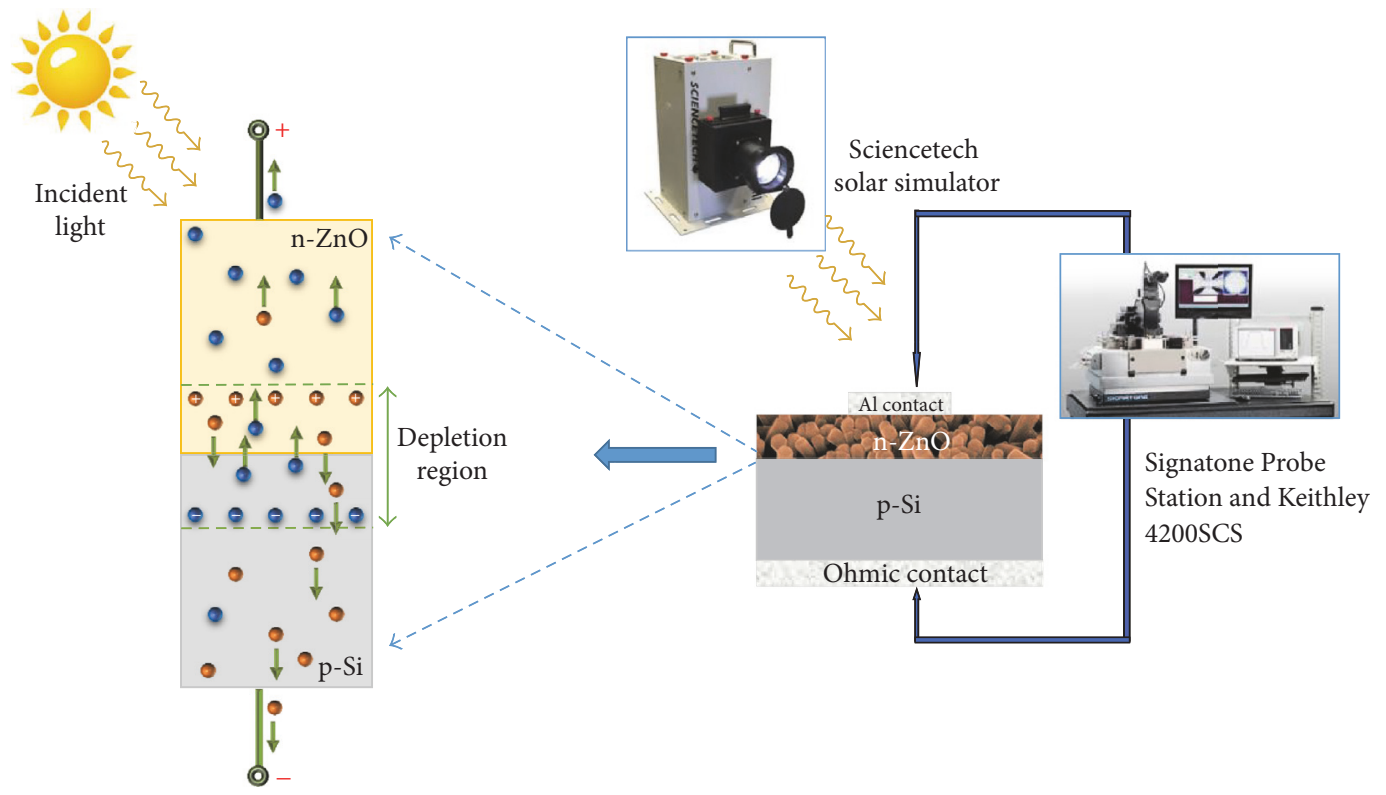

FIGURE 1: Schematic diagram and illustration of the work principle of the $p$-Si/n-ZnO-NRs photodiodes.

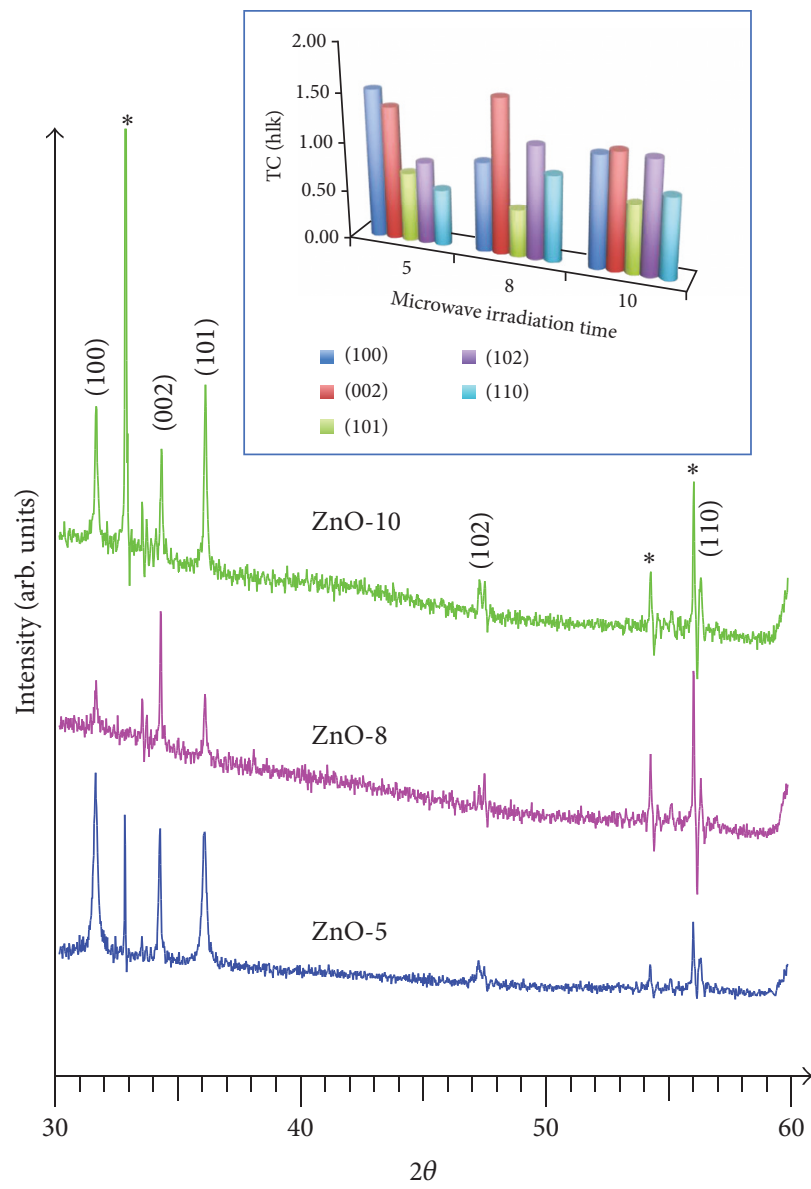

FIGURE 2: XRD spectra and the variation of TC(hkl) values (inset) of the ZnO-NRs films irradiated with different irradiation times $(*$ : $\mathrm{p}$-Si substrate). 


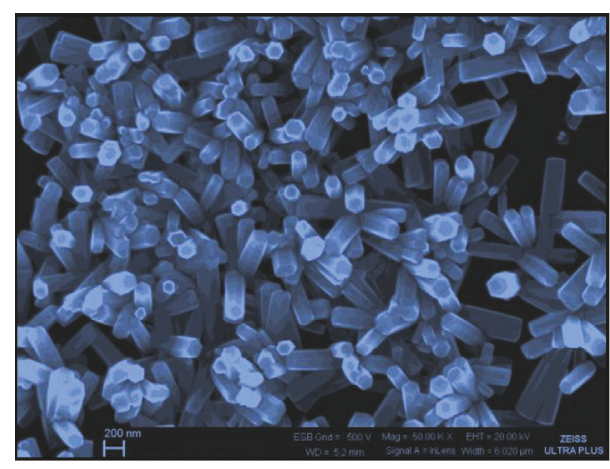

(a)

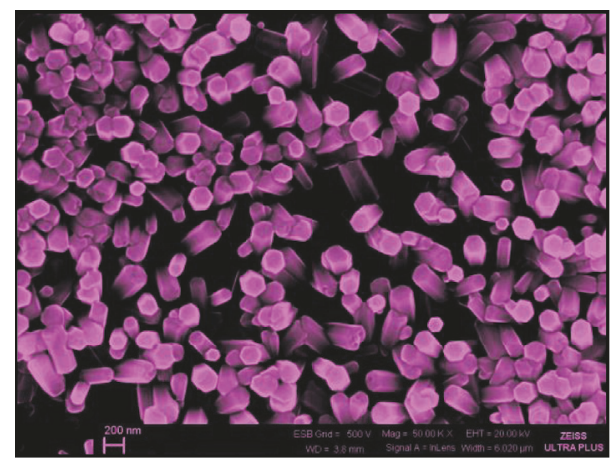

(c)

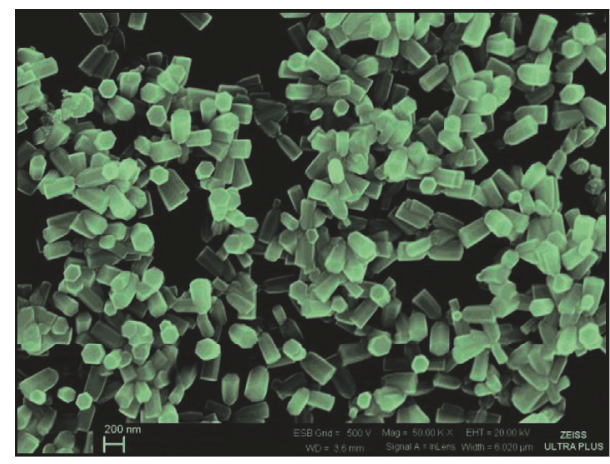

(e)

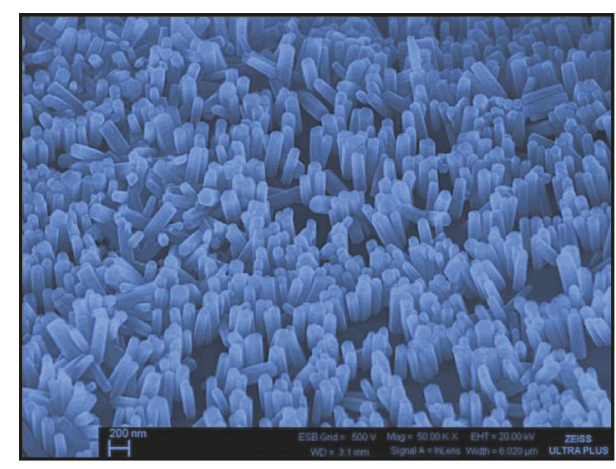

(b)

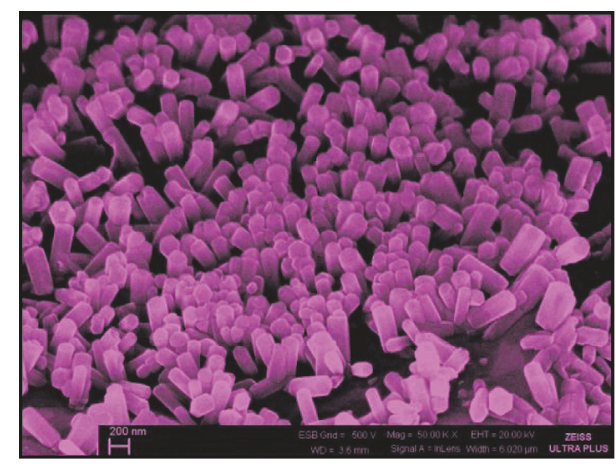

(d)

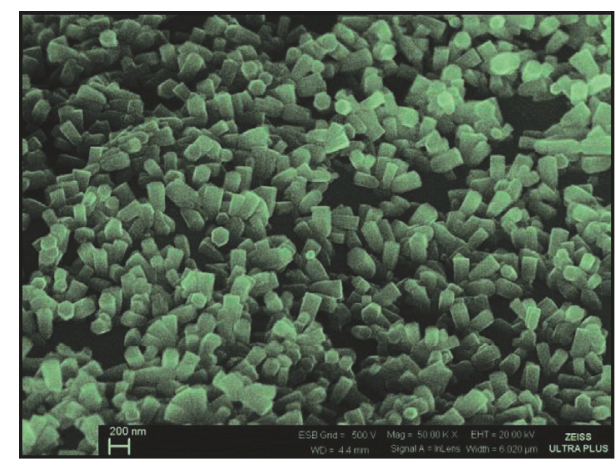

(f)

Figure 3: Top view ((a)-(c)) and 50 -tilted view ((d)-(f)) of FESEM images for the ZnO-NRs films depending on the increased three different irradiation times.

is a bit more than the others, resulting in deterioration in the surface coating. As seen from $50^{\circ}$-tilted views in Figure 3, the length of the observed hexagonal nanorods decreases slightly depending on the increase in the irradiation time. The average lengths of hexagonal nanorods for each irradiation time were measured from the both top and tilted images and these values are approximately $550 \mathrm{~nm}, 450 \mathrm{~nm}$, and $300 \mathrm{~nm}$ for $\mathrm{ZnO}-5, \mathrm{ZnO}-8$, and $\mathrm{ZnO}-10$, respectively. Although any significant change in the diameter of the nanorods is not observed, it is seen that the diameters of the nanorods slightly increase, especially at $\mathrm{ZnO}-8$ and $\mathrm{ZnO}-10$, as decreasing their lengths. Furthermore, the obtained XRD and SEM results for three samples support each other greatly.

Basically, a photodiode is a device which converts incident light into an electric current by generating electron-hole pairs due to the absorption of light in the depletion region of $\mathrm{p}-\mathrm{n}$ junction. In Figure 1 , the working principle of a $\mathrm{p}$ $\mathrm{n}$ junction photodiode is illustrated simply. As seen in this illustration, as a result of the absorption of the incident light in the depletion region, the inbuilt electric field of the depletion region causes the carriers to move away from the junction and photocurrent is generated. Since the total current of a photodiode consists of the sum of photocurrents and dark currents, the dark current must be reduced to increase the sensitivity of the photodiode [32-34]. Figure 4 shows current-voltage $(I-V)$ characteristics of the $p-S i / n$ $\mathrm{ZnO}-\mathrm{NRs}$ photodiodes under dark and various illumination intensities. As seen in these figures, the current of the diodes in the reverse bias region increases with light illumination intensity, whereas the forward current does not change with 


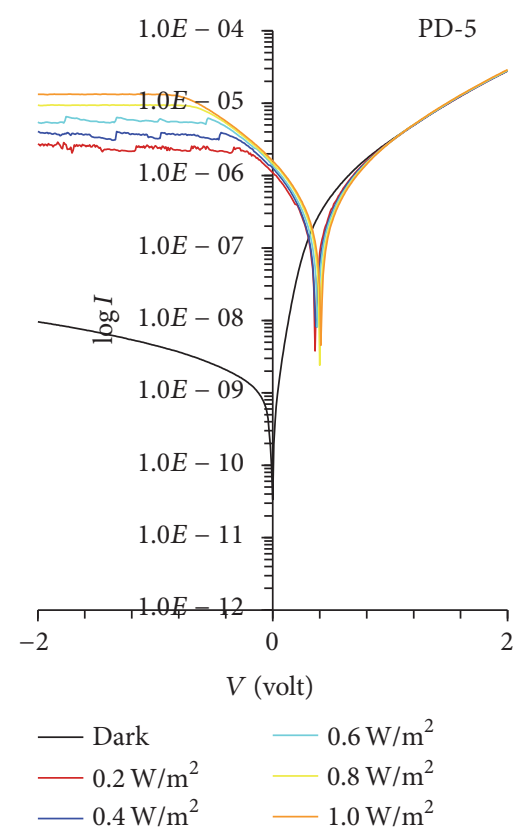

(a)

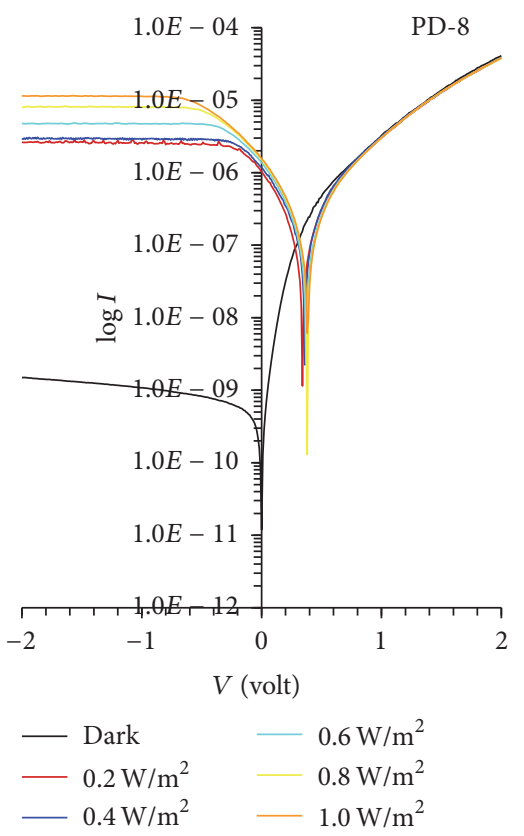

(b)

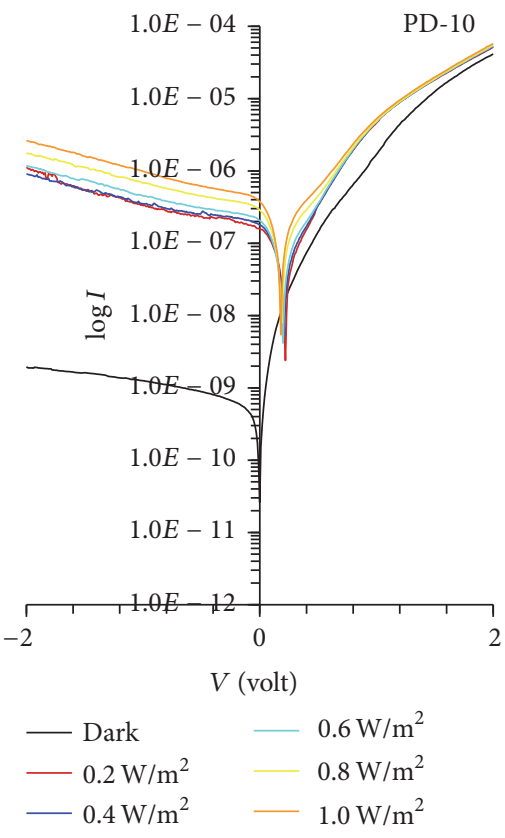

(c)

Figure 4: $I-V$ plots of the $p-S i / n-Z n O-N R s$ photodiodes.

the illumination. This indicates that photons create electronhole pairs and the separation of photogenerated electronhole pairs in reverse bias region is more effective than that of forward bias region. Therefore, the diodes exhibit the conventional photoconducting mechanism. As seen in Figure 4, among the three different photodiodes, PD-8 stands out within the scope of the generated photocurrent in the reverse bias region.

The $I-V$ characteristics can be analyzed by thermionic emission theory by Bethe [35] that the current density of majority carriers over the potential barrier in this theory is expressed as

$$
I=I_{0} \exp \left(\frac{q\left(V-I R_{s}\right)}{n k T}\right),
$$

where $q$ is the electronic charge, $V$ is the applied voltage, $k$ is the Boltzmann constant, $n$ is the ideality factor, $T$ is the temperature, $R_{s}$ is the series resistance, and $I_{0}$ is the reverse saturation current. Thanks to this saturation current, the barrier height $\left(\phi_{b}\right)$ of the diodes can be calculated by the following relation:

$$
I_{0}=A A^{*} T^{2} \exp \left(\frac{-q \phi_{b}}{k T}\right)
$$

where $A$ is the diode contact area and $A^{*}$ is the Richardson constant $\left(32 \mathrm{~A} / \mathrm{cm}^{2} \mathrm{~K}^{2}\right.$ for $\left.\mathrm{p}-\mathrm{Si}\right)$. The $\phi_{b}$ and $n$ values of the photodiodes were determined from the intercepts and slopes of the forward bias and given in Table 1. The ideality factor values higher than unity are indicator of a nonideal diode behavior, but these values calculated less than or close to 2 are acceptable when the production method and the diode
TABLE 1: Electrical parameters obtained from $I-V$ characteristics and Norde equation for the photodiodes.

\begin{tabular}{lcccc}
\hline \multirow{2}{*}{ Diode code } & \multicolumn{2}{c}{$I$-V characteristics } & \multicolumn{2}{c}{ Norde equation } \\
& $n$ & $\phi_{b}(\mathrm{eV})$ & $R_{s}(\mathrm{ohm})$ & $\phi_{b}(\mathrm{eV})$ \\
\hline PD-5 & 1.88 & 0.77 & $5.06 \times 10^{6}$ & 0.81 \\
PD-8 & 1.74 & 0.78 & $1.51 \times 10^{7}$ & 0.83 \\
PD-10 & 2.11 & 0.78 & $5.05 \times 10^{7}$ & 0.79 \\
\hline
\end{tabular}

TABLE 2: Photovoltaic parameters of the photodiodes.

\begin{tabular}{lcccc}
\hline $\begin{array}{l}\text { Diode } \\
\text { code }\end{array}$ & $V_{\text {oc }}(\mathrm{mV})$ & $I_{\text {sc }}(\mu A)$ & $\begin{array}{c}I_{\text {photo }} / I_{\text {dark }}(-2 \mathrm{~V}) \\
100 \mathrm{~mW} / \mathrm{cm}^{2}\end{array}$ & $\mathrm{RR}$ \\
\hline PD-5 & 420 & 1.59 & 1376 & $2.94 \times 10^{3}$ \\
PD-8 & 390 & 1.56 & 7600 & $2.74 \times 10^{4}$ \\
PD-10 & 180 & 0.38 & 1333 & $2.12 \times 10^{4}$ \\
\hline
\end{tabular}

are thought to have heterojunction structure. The transport mechanism of these diodes consists of defect-assisted tunneling with conventional electron-hole recombination. An increase in illumination intensity leads to formation of more free carriers with an associated increase in the photocurrent.

The open circuit voltage $\left(V_{\mathrm{oc}}\right)$ and short circuit current $\left(I_{\mathrm{sc}}\right)$ of the photodiode under $100 \mathrm{~mW} / \mathrm{cm}^{2}$ illumination are given in Table 2. The diode demonstrates a photoresponse behavior having low $V_{\mathrm{oc}}$, low $I_{\mathrm{sc}}$, and high photocurrent values. Naturally, the reason of this photoelectric effect in the structure is due to the light-induced electron generation at the depletion region [36]. 
To determine the photosensitivity of the photodiodes, $I_{\text {photo }} / I_{\text {dark }}$ (photosensitivity) values under $-2 \mathrm{~V}$ were determined and are given in Table 2. As seen in this table, the PD-8 photodiode exhibited the highest photosensitivity as previously observed in Figure 4. The illumination of the diode causes creating photogenerated charge carriers and an increase in the illumination increases the number of these carriers contributing to the current. After the terminating of the illumination, the number of free electrons is decreased and accordingly the current of the diode is also decreased. The trap centers present in the $\mathrm{ZnO}$ material play a crucial role to determine the photoconducting properties of the diode. Also, the reason of having maximum photosensitivity of PD- 8 is to have a highest photocurrent and lowest dark current. The low photosensitivity values for PD-5 and PD-10 arise from the high dark current of PD-5 and the low photocurrent of PD-10, respectively. Actually, making a correlation between the $\mathrm{ZnO}-\mathrm{NRs}$ properties and photodiode performance or explaining the exact reason of these results are difficult according to our results but we can say that the coating properties of the surface play an important role in the diode performance, because, as mentioned before in XRD and SEM results, the disappearing of Si peak at 32.7 degrees and being more dominant (002) preferred orientation in the XRD pattern of PD- 8 show that the coating of PD- 8 is better than the others. Also, according to the detailed SEM investigations, a little more voids on the surface of PD-10 may be the cause of reduction in photocurrent of PD-10.

For further evaluation of the photosensitivity behavior of the diode, the variation of photocurrent depending on the illumination intensity was investigated. In order to analyze the photoconducting mechanism, we used the following relation:

$$
I_{\mathrm{PH}}=\alpha P^{m},
$$

where $\alpha$ is a constant, $I_{\mathrm{PH}}$ is the photocurrent, $m$ is an exponent, and $P$ is the illumination intensity. Setting $\alpha=10^{\beta}$ where $\beta$ is also constant and taking logarithms of both sides of (3) give

$$
\log I_{\mathrm{PH}}=m \log P+\beta
$$

and to deduce the exponent of the illumination intensity, loglog plot of diode current versus illumination intensity can be used. The plots of $\log \left(I_{\mathrm{PH}}\right)$ versus $\log (P)$ curves are shown in Figure 5. The obtained $m$ values of the photodiodes were 1.03 (for PD-5), 0.94 (for PD-8), and 0.69 (for PD-10). The obtained results may be evaluated as a result of the existence of a continuous distribution of localized states in the mobility gap of these materials [37, 38].

The rectification ratio $(\mathrm{RR})$ of the forward current $\left(I_{f}\right)$ to the reverse current $\left(I_{r}\right)$ at $\mp 2 \mathrm{~V}$ applied voltage was calculated and given in Table 2. The reverse current is as large as the forward current as the increase of bias and the calculated values are larger than other related works in the literature [3941].

The barrier height and series resistance values of the photodiodes can also be obtained using a method developed by Norde. The following function has been characterized by the modified Norde's method [42]:

$$
F(V)=\frac{V_{0}}{\gamma}-\frac{k T}{q} \ln \left(\frac{I(V)}{A^{*} A T^{2}}\right),
$$

where $\gamma$ is the integer (dimensionless) greater than $n$ and $I(V)$ is the current obtained from the $I-V$ characteristic. Once the minimum of the $F(V)$ versus $V$ plot is determined from Figure 6, the value of barrier height can be obtained from (6), where $F(V)$ is the minimum point of $F(V)$ and $V_{0}$ is the corresponding voltage.

$$
\phi_{b}=F\left(V_{0}\right)+\frac{V_{0}}{\gamma}-\frac{k T}{q} .
$$

The series resistance of the junctions can be calculated as follows:

$$
R_{s}=\frac{k T(\gamma-n)}{q I_{0}},
$$

where $I_{0}$ is the corresponding current. By using the Norde method, the barrier height and series resistance values of the diodes were calculated and presented in Table 1. As seen in this table, the barrier height values calculated by Norde are very close to that of obtained from $I-V$. The values of series resistance are considerably high and the reason of being high of these calculated values, as mentioned before in the experimental section, is most likely due to the fact that no any annealing process was applied to get low resistivity for back ohmic contact.

To investigate the $C-V$ characteristics of $p-S i / n-Z n O$ $N R s, C-V$ and $1 / C^{2}-V$ plots taken at different frequencies were used. These graphs obtained between $10 \mathrm{kHz}$ and $1 \mathrm{MHz}$ are shown in Figure 7. As seen in these figures, all graphs illustrate same trend; that is, the capacitance value increases with the applied bias voltage, and also depending on the increase in frequency, the capacitance decreases. At the same time, the highest capacitance values belong to $\mathrm{PD}-8$. In the range between $0.5 \mathrm{~V}$ and $1 \mathrm{~V}$, a linear behavior of $C-V$ curves has been observed and the reason of this linear behavior is the linear change in the depletion region of the heterojunction diode. Using the following relation, the $C-V$ characteristics of the obtained heterojunction diodes can be analyzed [43]

$$
\frac{1}{C^{2}}=\frac{2\left(V_{\mathrm{bi}}+V\right)}{A^{2} \varepsilon_{s} q N_{a}},
$$

where $V_{\mathrm{bi}}$ is the built-in potential, $\varepsilon_{s}$ is the dielectric constant of semiconductor $\left(\varepsilon_{s}=11.8\right)$, and $N_{a}$ is the acceptor concentration. From the $C-V$ measurements, the following relation was used to determine the barrier height of the diode [44],

$$
\phi_{b(C-V)}=\frac{V_{\mathrm{bi}}}{n}+\frac{k T}{q} \ln \left(\frac{N_{v}}{N_{a}}\right),
$$

where $N_{v}$ is density of states in the valence band $\left(N_{v}=\right.$ $\left.1.82 \times 10^{19} \mathrm{~cm}^{-3}\right)$. At the stage of calculation of barrier height, 


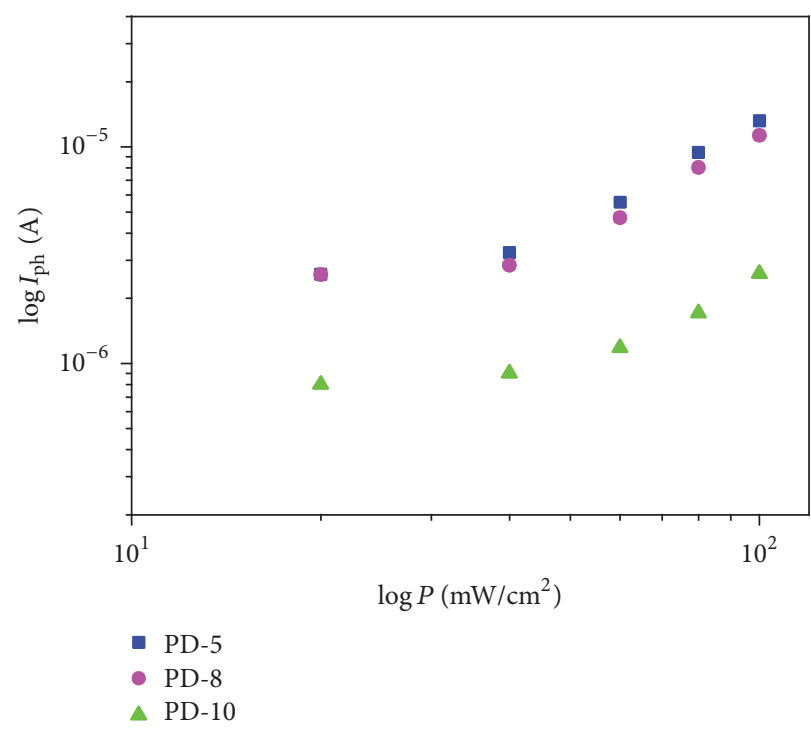

FIGURE 5: Photocurrent versus illumination intensity plot of $p$-Si/n-ZnO-NRs photodiodes.

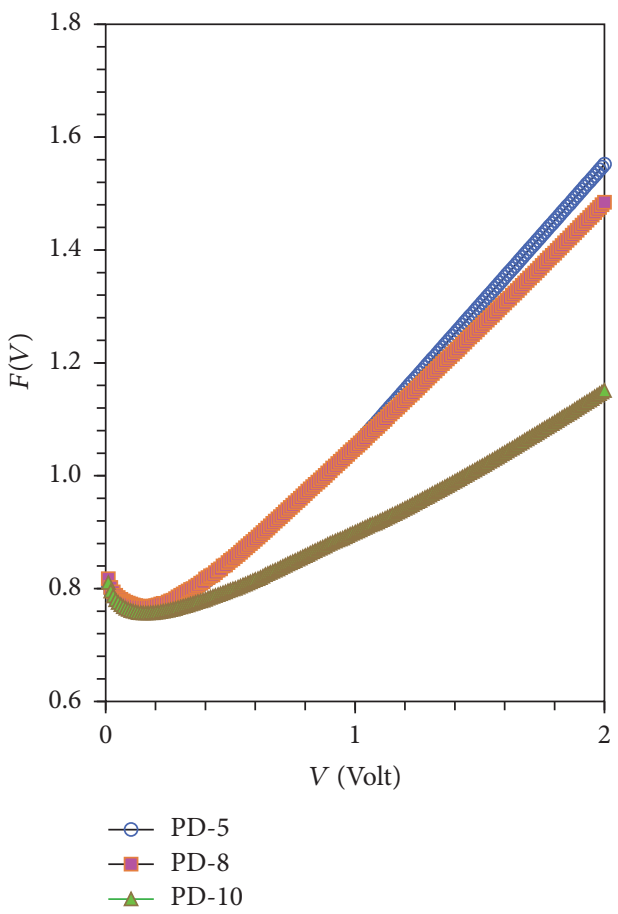

Figure 6: $F(V)$ versus $V$ plot of $p$-Si/n-ZnO-NRs photodiodes.

the $V_{\mathrm{bi}}$ and $N_{a}$ values obtained from $C^{-2}-V$ plots, which are shown in Figure 8, were used. The obtained values for $V_{\mathrm{bi}}$ and $\phi_{b}$ are given in Table 3 at different frequencies. As seen in this table, both $V_{\mathrm{bi}}$ and barrier height tend to increase with increasing frequency, and also, while $N_{a}$ values increase for PD-8, it decreases by about ten times in the PD-10. Considering the $\phi_{b}$ values obtained depending on the frequency from $C-V$, for PD-5 and PD-10, the values are larger than that of obtained from $I-V$, but PD-8's are smaller. Probably, the presence of trap states and oxide layer at interfacial layer of the device and inhomogeneity that can be observed in terms of charge distributions and thickness in the interfacial layer may have caused these differences between them [45-47]. The same reasons may have played an important role in the differences observed in $N_{a}$ values for three samples.

Figure 9 shows the variation of the series resistance of the fabricated $p-S i / n-Z n O-N R s$ photodiodes with applied bias. In this figure, a peak is observed and this peak decreases with increasing frequency, and also it shifts to the higher positive 

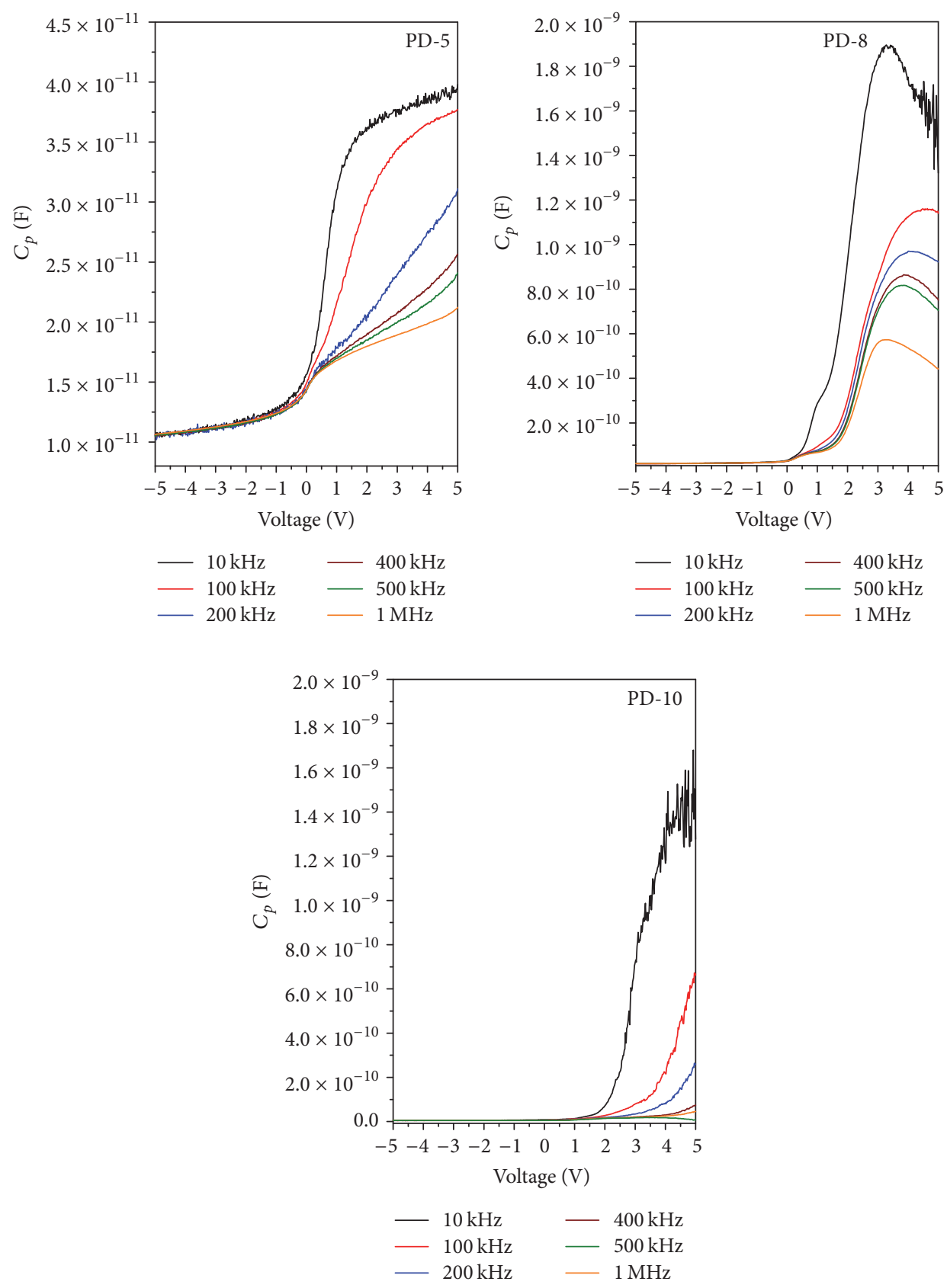

Figure 7: $C_{p}-V$ graphs of the $p-S i / n-Z n O-N R s$ photodiodes.

voltages. The decrease in the peak intensity and the shifting of this peak with increasing frequency mean that the interface charges follow the frequency of the applied voltage $[32,35]$.

\section{Conclusion}

To obtain ZnO-NRs, MW-CBD method was used. The structural and morphological properties of $\mathrm{ZnO}$-NRs were investigated depending on the microwave irradiation time $(5,8$, and $10 \mathrm{~min})$. The XRD spectra of all the films exhibited polycrystalline nature. According to the calculated TC values, a dominant preferred orientation was only observed for $\mathrm{ZnO}-8$ in (002) direction. The presence of randomly oriented $\mathrm{ZnO}$ nanorods for all the films was confirmed by FESEM results. Also, these results showed that the length of nanorods decreased slightly depending on the increase in the irradiation time. The $p-S i / n-\mathrm{ZnO}-\mathrm{NRs}$ heterojunction structures were fabricated and their electrical characterizations were performed. According to the obtained results, it was determined that these $p-n$ junctions exhibited both a good photosensitivity and photoconducting behavior with high photocurrent. Among these heterojunctions, the highest photosensitivity was determined to be 7600 for $p-S i / n-\mathrm{ZnO}$ NRs (PD8) photodiode. Through the $C-V$ measurements of $p$-Si/n-ZnO-NRs photodiodes, the barrier height and series resistance were calculated. The obtained results suggest that 

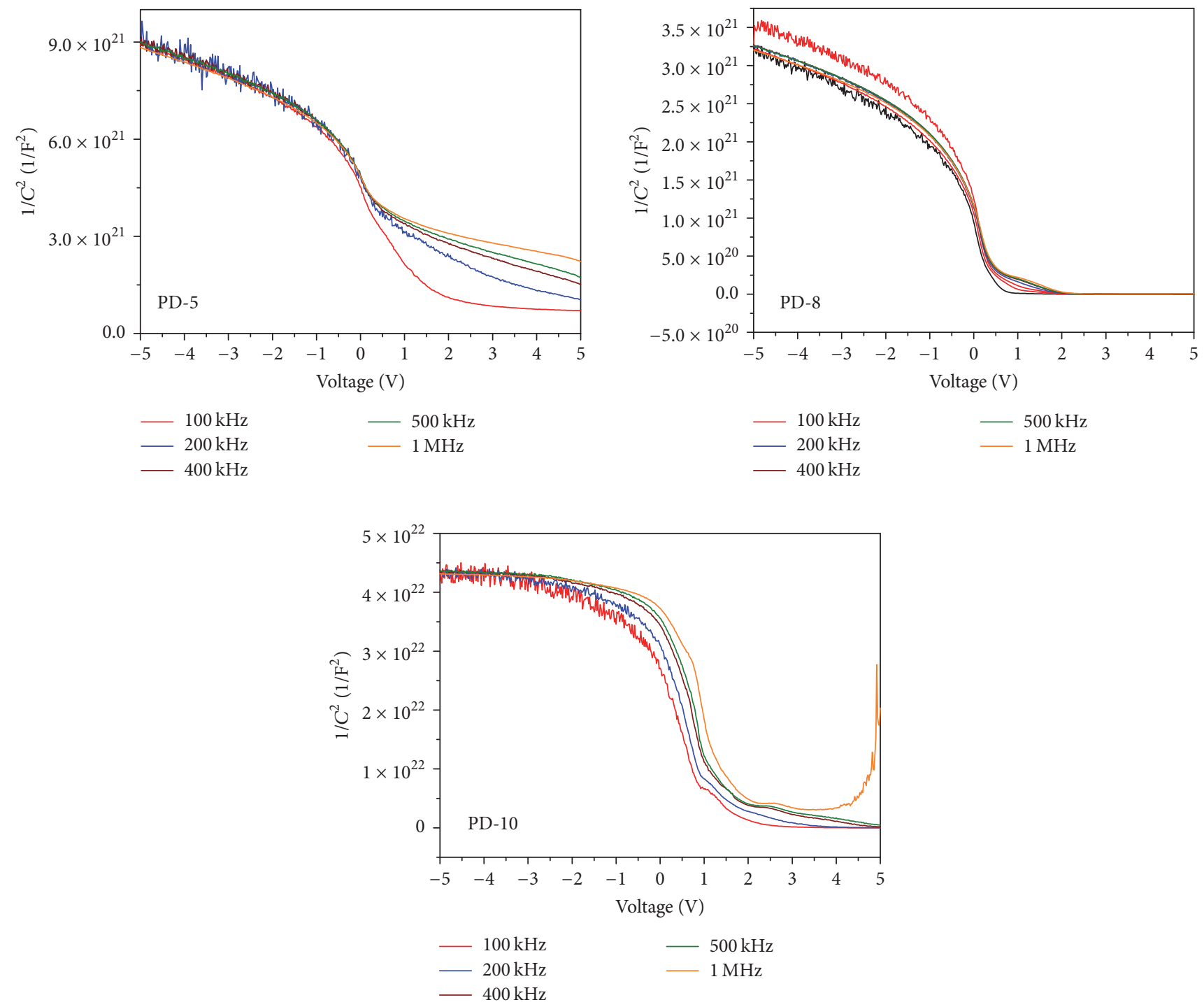

Figure 8: $1 / C^{2}-V$ graphs of the $p-S i / n-Z n O-N R s$ photodiodes.

TABLE 3: Electrical parameters calculated by $C-V$ measurements for the photodiodes.

\begin{tabular}{|c|c|c|c|c|}
\hline Diode code & Frequency $(\mathrm{kHz})$ & $N_{a}\left(\mathrm{~cm}^{-3}\right)$ & $V_{\mathrm{bi}}(\mathrm{V})$ & $\phi_{b}(\mathrm{eV})$ \\
\hline \multirow{5}{*}{ PD-5 } & 100 & $1.03 \times 10^{13}$ & 1.49 & 0.87 \\
\hline & 200 & $1.17 \times 10^{13}$ & 1.79 & 1.04 \\
\hline & 400 & $1.25 \times 10^{13}$ & 1.95 & 1.10 \\
\hline & 500 & $1.39 \times 10^{13}$ & 2.15 & 1.17 \\
\hline & 1000 & $1.32 \times 10^{13}$ & 2.06 & 1.14 \\
\hline \multirow{5}{*}{ PD-8 } & 100 & $1.50 \times 10^{13}$ & 0.57 & 0.57 \\
\hline & 200 & $2.09 \times 10^{13}$ & 0.73 & 0.63 \\
\hline & 400 & $1.97 \times 10^{13}$ & 0.70 & 0.62 \\
\hline & 500 & $1.84 \times 10^{13}$ & 0.66 & 0.60 \\
\hline & 1000 & $2.02 \times 10^{13}$ & 0.72 & 0.62 \\
\hline \multirow{5}{*}{ PD-10 } & 100 & $6.27 \times 10^{12}$ & 0.51 & 0.58 \\
\hline & 200 & $1.08 \times 10^{12}$ & 1.20 & 0.88 \\
\hline & 400 & $1.23 \times 10^{12}$ & 1.49 & 0.99 \\
\hline & 500 & $1.13 \times 10^{12}$ & 1.49 & 0.99 \\
\hline & 1000 & $1.14 \times 10^{12}$ & 1.69 & 1.07 \\
\hline
\end{tabular}



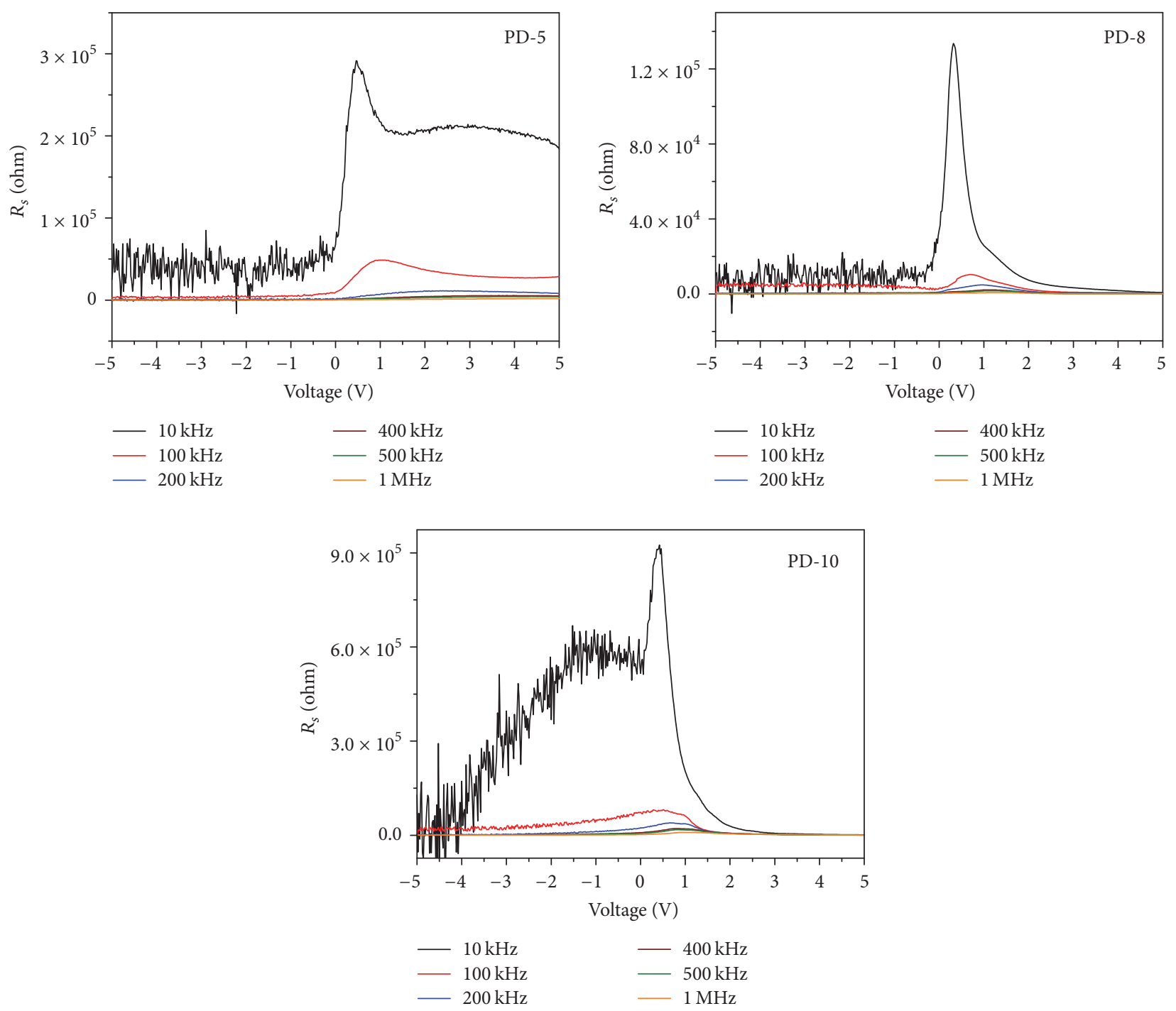

FIGURE 9: $R_{s}-V$ graphs of the $p-S i / n-Z n O-N R s$ photodiodes.

the $p$-Si/n-ZnO-NRs photodiodes can be used as a sensor in the optoelectronic applications.

\section{Conflicts of Interest}

The authors declare that they have no conflicts of interest.

\section{Acknowledgments}

This work was supported by Anadolu University Commission of Scientific Research Projects under Grant nos. 1305F082 and 1402 F055.

\section{References}

[1] J. J. Hassan, M. A. Mahdi, C. W. Chin, H. Abu-Hassan, and Z. Hassan, "A high-sensitivity room-temperature hydrogen gas sensor based on oblique and vertical $\mathrm{ZnO}$ nanorod arrays," Sensors and Actuators B: Chemical, vol. 176, pp. 360-367, 2013.

[2] S. Öztürk, N. Kilinç, and Z. Z. Öztürk, "Fabrication of ZnO nanorods for NO2 sensor applications: Effect of dimensions and electrode position," Journal of Alloys and Compounds, vol. 581, pp. 196-201, 2013.

[3] J. J. Hassan, M. A. Mahdi, A. Ramizy, H. Abu Hassan, and Z. Hassan, "Fabrication and characterization of $\mathrm{ZnO}$ nanorods/p$6 \mathrm{H}-\mathrm{SiC}$ heterojunction LED by microwave-assisted chemical bath deposition," Superlattices and Microstructures, vol. 53, no. 1, pp. 31-38, 2013.

[4] A. Baltakesmez, S. Tekmen, P. Ko, S. Tuzemen, K. Meral, and Y. Onganer, "UV-visible detector and LED based $\mathrm{n}-\mathrm{ZnO} / \mathrm{p}$ Si heterojunction formed by electrodeposition," AIP Advances, vol. 3, no. 3, Article ID 032125, 2013.

[5] S. Ruzgar, A. E. Ozkan, M. Caglar et al., "Effect of the deposition temperature on the device performance of the nanostructured $\mathrm{ZnO}$ thin film transistor by sol gel method," Journal of Nanoelectronics and Optoelectronics, vol. 9, no. 5, pp. 689-693, 2014.

[6] F. Yakuphanoglu, "Evaluation of photoresponse in solutionprocessable $\mathrm{ZnO}$ thin film transistor for radiative sensor applications," Sensors and Actuators, A: Physical, vol. 173, no. 1, pp. 141-144, 2012.

[7] P. S. Shewale and Y. S. Yu, "Structural, surface morphological and UV photodetection properties of pulsed laser deposited 
Mg-doped $\mathrm{ZnO}$ nanorods: Effect of growth time," Journal of Alloys and Compounds, vol. 654, pp. 79-86, 2016.

[8] P. Tao, W. Guo, J. Du, C. Tao, S. Qing, and X. Fan, "Continuous wet-process growth of $\mathrm{ZnO}$ nanoarrays for wire-shaped photoanode of dye-sensitized solar cell," Journal of Colloid and Interface Science, vol. 478, pp. 172-180, 2016.

[9] J. X. Wang, Y. Yang, and X. W. Sun, "ZnO disk-like structures and their application in dye sensitized solar cell," Solid State Communications, vol. 240, pp. 46-52, 2016.

[10] M. Caglar and S. Ruzgar, "Influence of the deposition temperature on the physical properties of high electron mobility $\mathrm{ZnO}$ films by sol-gel process," Journal of Alloys and Compounds, vol. 644, pp. 101-105, 2015.

[11] M. Kashif, U. Hashim, M. E. Ali, K. L. Foo, and S. M. Usman Ali, "Morphological, structural, and electrical characterization of sol-gel-synthesized ZnO nanorods," Journal of Nanomaterials, vol. 2013, Article ID 478942, 7 pages, 2013.

[12] I. S. Yahia, A. A. M. Farag, M. Cavas, and F. Yakuphanoglu, "Effects of stabilizer ratio on the optical constants and optical dispersion parameters of $\mathrm{ZnO}$ nano-fiber thin films," Superlattices and Microstructures, vol. 53, no. 1, pp. 63-75, 2013.

[13] C. Manoharan, S. Dhanapandian, A. Arunachalam, and M. Bououdina, "Physical properties of spray pyrolysized nano flower $\mathrm{ZnO}$ thin films," Journal of Alloys and Compounds, vol. 685, pp. 395-401, 2016.

[14] A. Bedia, F. Z. Bedia, M. Aillerie et al., "Optical, electrical and structural properties of nano-pyramidal $\mathrm{ZnO}$ films grown on glass substrate by spray pyrolysis technique," Optical Materials, vol. 36, no. 7, pp. 1123-1130, 2014.

[15] S. Kahraman, F. Bayansal, H. A. Çetinkara, H. M. Çakmak, and H. S. Güder, "Characterization of CBD grown $\mathrm{ZnO}$ films with high c-axis orientation," Materials Chemistry and Physics, vol. 134, no. 2-3, pp. 1036-1041, 2012.

[16] S. B. Jambure, S. J. Patil, A. R. Deshpande, and C. D. Lokhande, "A comparative study of physico-chemical properties of CBD and SILAR grown $\mathrm{ZnO}$ thin films," Materials Research Bulletin, vol. 49, no. 1, pp. 420-425, 2014.

[17] A. Arslan, E. Hür, S. Ilican, Y. Caglar, and M. Caglar, "Controlled growth of c-axis oriented $\mathrm{ZnO}$ nanorod array films by electrodeposition method and characterization," Spectrochimica Acta-Part A: Molecular and Biomolecular Spectroscopy, vol. 128, pp. 716-723, 2014.

[18] N. Kicir, T. Tüken, O. Erken, C. Gumus, and Y. Ufuktepe, "Nanostructured $\mathrm{ZnO}$ films in forms of rod, plate and flower: Electrodeposition mechanisms and characterization," Applied Surface Science, vol. 377, pp. 191-199, 2016.

[19] V. Bhardwaj, R. Chowdhury, and R. Jayaganthan, "Nanomechanical and microstructural characterization of sputter deposited ZnO thin films," Applied Surface Science, vol. 389, pp. 1023-1032, 2016.

[20] S. Kunj and K. Sreenivas, "Residual stress and defect content in magnetron sputtered $\mathrm{ZnO}$ films grown on unheated glass substrates," Current Applied Physics, vol. 16, no. 7, pp. 748-756, 2016.

[21] N. Y. Yuan, S. Y. Wang, C. B. Tan, X. Q. Wang, G. G. Chen, and J. N. Ding, "The influence of deposition temperature on growth mode, opticaland mechanical properties of $\mathrm{ZnO}$ films prepared by the ALD method," Journal of Crystal Growth, vol. 366, pp. 43-46, 2013.

[22] M. Caglar and K. Gorgun, "Characterization and heterojunction application of nanorod structure $\mathrm{ZnO}$ films prepared by microwave assisted chemical bath deposition method without any template," Journal of Nanoelectronics and Optoelectronics, vol. 11, no. 6, pp. 769-776, 2016.

[23] Y. Y. Villanueva, D. Liu, and P. T. Cheng, "Pulsed laser deposition of zinc oxide," Thin Solid Films, vol. 501, no. 1-2, pp. 366$369,2006$.

[24] O. F. Farhat, M. M. Halim, N. M. Ahmed, and M. A. Qaeed, "ZnO nanofiber (NFs) growth from $\mathrm{ZnO}$ nanowires (NWs) by controlling growth temperature on flexible Teflon substrate by CBD technique for UV photodetector," Superlattices and Microstructures, vol. 100, pp. 1120-1127, 2016.

[25] A. M. Peiró, C. Domingo, J. Peral et al., "Nanostructured zinc oxide films grown from microwave activated aqueous solutions," Thin Solid Films, vol. 483, no. 1-2, pp. 79-83, 2005.

[26] I. Orak, A. Kocyigit, and A. Turut, “The surface morphology properties and respond illumination impact of $\mathrm{ZnO} / \mathrm{n}-\mathrm{Si}$ photodiode by prepared atomic layer deposition technique," Journal of Alloys and Compounds, vol. 691, pp. 873-879, 2017.

[27] N. H. Al-Hardan, A. Jalar, M. A. A. Hamid, L. K. Keng, N. M. Ahmed, and R. Shamsudin, "A wide-band UV photodiode based on $\mathrm{n}-\mathrm{ZnO} / \mathrm{p}-\mathrm{Si}$ heterojunctions," Sensors and Actuators, A: Physical, vol. 207, pp. 61-66, 2014.

[28] F. Yakuphanoglu, Y. Caglar, M. Caglar, and S. Ilican, “ ZnO/p$\mathrm{Si}$ heterojunction photodiode by solgel deposition of nanostructure $\mathrm{n}-\mathrm{ZnO}$ film on $\mathrm{p}$-Si substrate," Materials Science in Semiconductor Processing, vol. 13, no. 3, pp. 137-140, 2010.

[29] Z. Yuan and Y. Ren, "Fabrication and characteristics of photodiode based on $\mathrm{ZnO}$ nanowire arrays and spray-coated regioregular P3HT layers," Physica E: Low-Dimensional Systems and Nanostructures, vol. 48, pp. 128-132, 2013.

[30] S. O. Tan, H. Uslu Tecimer, O. Çiçek, H. Tecimer, İ. Orak, and Ş. Altındal, "Electrical characterizations of $\mathrm{Au} / \mathrm{ZnO} / \mathrm{n}-\mathrm{GaAs}$ Schottky diodes under distinct illumination intensities," Journal of Materials Science: Materials in Electronics, pp. 1-8, 2016.

[31] C. S. Barrett and T. B. Massalski, "Structure of Metals," 1980.

[32] M. Shur, Introduction to Electronic Devices, Wiley and Sons, New York, NY, USA, 1996.

[33] M. S. Tyagi, Introduction to Semiconductor Materials and Devices, J. Wiley and Sons Inc., Canada, 1991.

[34] J. R. Antoni Rogalski, Narrow-Gap Semiconductor Photodiodes, SPIE Press, Washington, DC, USA, 2000.

[35] H. A. Bethe, "Theory of the boundary layer of crystal rectifiers," Radiation Laboratory Report 43-12, Radiation Laboratory, Cambridge, Mass, USA, 1942.

[36] A. A. M. Farag, "Influence of temperature and illumination on the characteristics of nanocrystalline Ga0.29 Al0.71As based heterojunction prepared by MOCVD," Journal of Alloys and Compounds, vol. 509, no. 31, pp. 8056-8064, 2011.

[37] R. Ocaya, A. G. Al-Sehemi, A. Al-Ghamdi, F. El-Tantawy, and F. Yakuphanoglu, "Organic semiconductor photosensors," Journal of Alloys and Compounds, vol. 702, pp. 520-530, 2017.

[38] A. Rose, "Concepts in photoconductivity," 1960.

[39] V. K. Sahu, P. Misra, R. S. Ajimsha, A. K. Das, and B. Singh, "Effect of growth temperature on diode parameters of $\mathrm{n}-\mathrm{ZnO} / \mathrm{p}$ Si heterojuction diodes grown by atomic layer deposition," Materials Science in Semiconductor Processing, vol. 54, pp. 1-5, 2016.

[40] J. Lv, Y. Sun, M. Zhao et al., "Rectifying properties of $\mathrm{ZnO}$ thin films deposited on FTO by electrodeposition technique," Applied Surface Science, vol. 366, pp. 348-352, 2016. 
[41] A. Rakhshani, "Characterization and device applications of p-type $\mathrm{ZnO}$ films prepared by thermal oxidation of sputterdeposited zinc oxynitride," Journal of Alloys and Compounds, vol. 695, pp. 124-132, 2017.

[42] H. Norde, "A modified forward I-V plot for Schottky diodes with high series resistance," Journal of Applied Physics, vol. 50, no. 7, pp. 5052-5053, 1979.

[43] S. M. Sze, Physics of Semiconductor Devices, Wiley, New York, NY, USA, 2nd edition, 1981.

[44] E. H. Rhoderick and R. H. Willams, Metal-Semiconductor Contact, Clarendon, Oxford, UK, 1988.

[45] Ş. Karataş and A. Türüt, "The determination of interface state energy distribution of the $\mathrm{H}$-terminated $\mathrm{Zn} / \mathrm{p}$-type $\mathrm{Si}$ Schottky diodes with high series resistance by the admittance spectroscopy," Vacuum, vol. 74, no. 1, pp. 45-53, 2004.

[46] F. Yakuphanoglu, "Electrical characterization and device characterization of $\mathrm{ZnO}$ microring shaped films by sol-gel method," Journal of Alloys and Compounds, vol. 507, no. 1, pp. 184-189, 2010.

[47] A. G. Imer, A. Tombak, and A. Korkut, "Electrical and photoelectrical characteristic investigation of a new generation photodiode based on bromothymol blue dye," Journal of Physics: Conference Series, vol. 707, no. 1, Article ID 012012, 2016. 

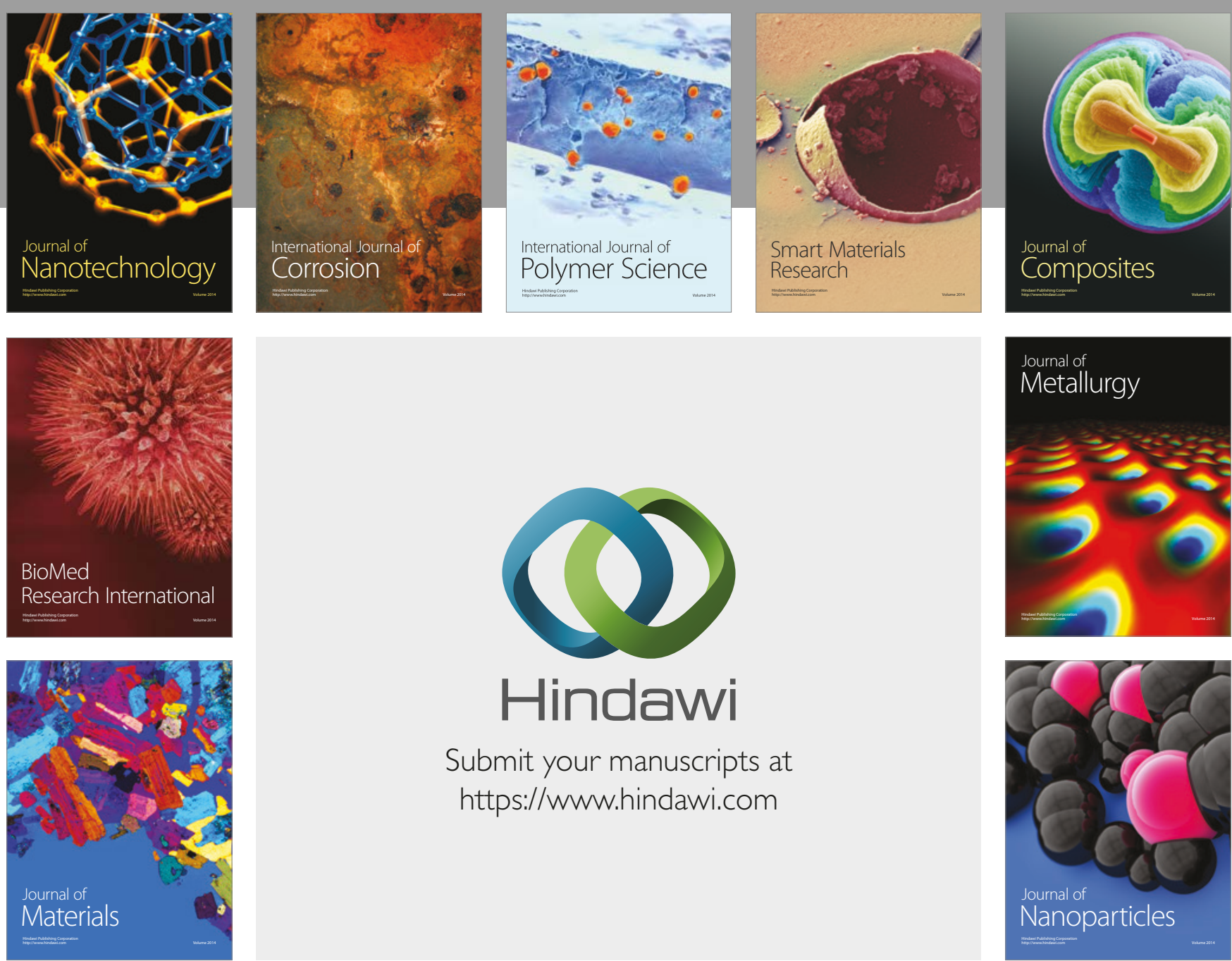

\section{Hindawi}

Submit your manuscripts at

https://www.hindawi.com
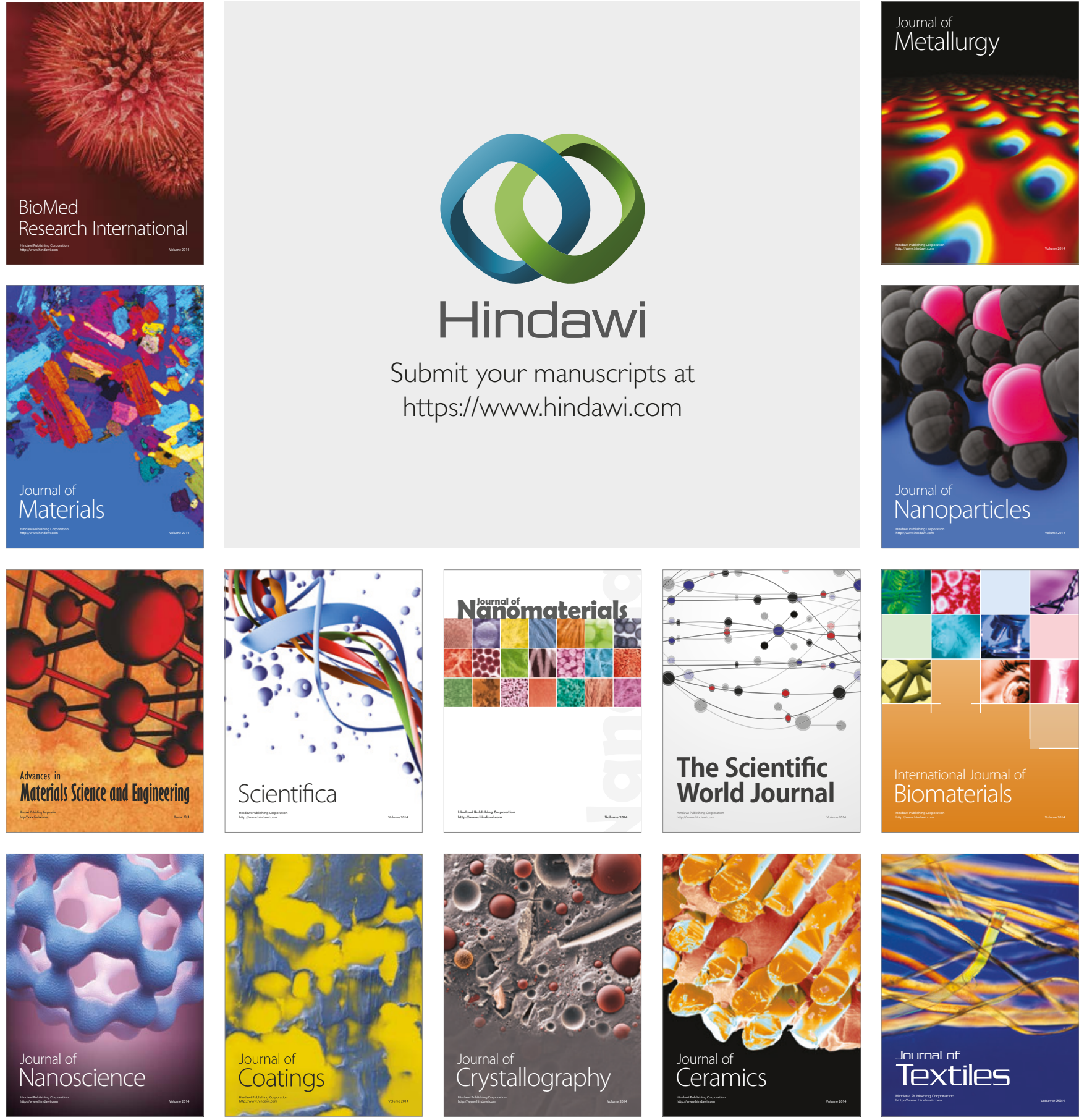

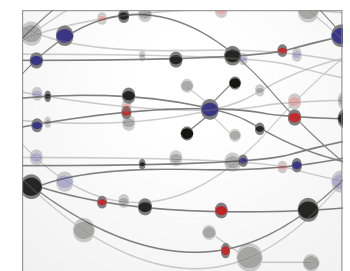

The Scientific World Journal
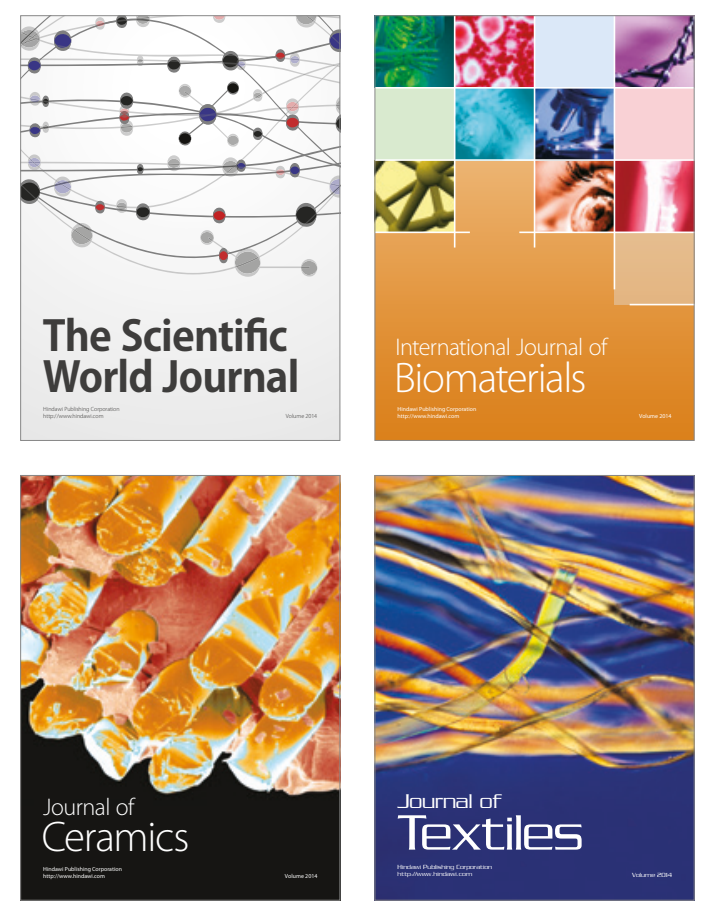